University of Nebraska - Lincoln

DigitalCommons@University of Nebraska - Lincoln

Faculty Publications, Department of Psychology

Psychology, Department of

2020

\title{
An Integrated Relational Framework of Depressed Mood and Anhedonia During Pregnancy
}

\author{
Rebecca L. Brock \\ University of Nebraska-Lincoln, rebecca.brock@unl.edu \\ Molly Franz \\ University of Nebraska-Lincoln, mollyrfranz@gmail.com \\ Erin L. Ramsdell \\ University of Nebraska-Lincoln
}

Follow this and additional works at: https://digitalcommons.unl.edu/psychfacpub

Part of the Marriage and Family Therapy and Counseling Commons, and the Psychology Commons

Brock, Rebecca L.; Franz, Molly; and Ramsdell, Erin L., "An Integrated Relational Framework of Depressed Mood and Anhedonia During Pregnancy" (2020). Faculty Publications, Department of Psychology. 1059. https://digitalcommons.unl.edu/psychfacpub/1059

This Article is brought to you for free and open access by the Psychology, Department of at DigitalCommons@University of Nebraska - Lincoln. It has been accepted for inclusion in Faculty Publications, Department of Psychology by an authorized administrator of DigitalCommons@University of Nebraska - Lincoln. 


\title{
An Integrated Relational Framework of Depressed Mood and Anhedonia During Pregnancy
}

\author{
Rebecca L. Brock, Molly R. Franz, \& Erin L. Ramsdell \\ University of Nebraska-Lincoln \\ Correspondence - R. L. Brock, Department of Psychology, University of Nebraska-Lincoln, \\ 238 Burnett Hall, Lincoln, NE 68588-0308; rebecca.brock@unl.edu \\ ORCID \\ Rebecca L. Brock https://orcid.org/o000-0001-7826-6421 \\ Molly R. Franz https://orcid.org/00oo-0001-7377-2296
}

\begin{abstract}
Objective: The aim of the present study was to test a unified framework that integrates several theories into a cohesive model to explain the interplay between neuroticism and intimate relationship quality as risk factors for prenatal depression.

Background: There is a notable spike in risk for depression during pregnancy, and the processes unfolding in the interparental relationship during this important time in the family life cycle might serve to mitigate or enhance this risk. Yet there is a need for theory-driven research integrating multiple conceptual frameworks to explicate the role of intimate relationship quality in depression.

Method: In a sample of 154 pregnant, cohabiting couples, multiple domains of intimate relationship quality were assessed using a semistructured clinical interview. An ecologically valid assessment of core depressive features was implemented, such that daily reports of depressed mood and anhedonia captured the pervasiveness of those symptoms for 2 weeks.
\end{abstract}

Published in Journal of Marriage and Family 82 (June 2020), pp 1056-1072

DOI:10.1111/jomf.12611

Copyright (C) National Council on Family Relations; published by Wiley. Used by permission. Submitted 5 December 2018; revised \& accepted 22 August 2019; published 14 October 2019. 
Results: The hypothesized, integrated model was supported for the following two dimensions of intimate relationship quality: conflict management for women and partner support for men. Neuroticism predicted depressive symptoms indirectly through poorer relationship quality and interacted with poorer relationship quality to influence depressive symptoms. In addition, poor sexual quality predicted paternal depressive symptoms, and this effect intensified at higher levels of neuroticism; however, neuroticism did not predict sexual quality.

Conclusions: This integrated approach to studying risk for depression has implications for future research and clinical practice, particularly for clinicians working with pregnant couples when one or both partners are experiencing symptoms of depression.

Keywords: couples, couples therapy, depression, family dynamics, family stress.

Depression is among the leading causes of disability nationwide, with approximately $6.7 \%$ of all adults experiencing at least one major depressive episode per year (Substance Abuse and Mental Health Services Administration, 2017). Depression is associated with a reduced quality of life as well as functional impairment across multiple domains (e.g., Rapaport, Clary, Fayyad, \& Endicott, 2005). Beyond the affected individual, depression places a substantial burden on families (Kiernan \& Mensah, 2009) and profoundly impacts child development (Letourneau, Tramonte, \& Willms, 2013). Indeed, as early as infancy, children of depressed parents are more likely to show difficulty regulating emotions, display impaired cognitive capacities, and demonstrate insecure attachment (for a review, see Speranza, Ammaniti, \& Trentini, 2006). In addition, there is a notable spike in risk for depression during the perinatal period (for a meta-analysis, see Gaynes et al., 2005). The primary goal of the present study was to integrate several etiological theories of depression within a unified framework to delineate the ways in which innate vulnerabilities influence and interact with intimate relationship quality during pregnancy to impact depressive symptoms.

\section{Relevant Frameworks for Understanding Risk for Depression During Pregnancy}

Much of the research linking intimate relationship discord to perinatal depression has been limited in scope and largely focused on the 
robust link between poor marital adjustment and postpartum maternal depression (e.g., for reviews, see O'Hara \& McCabe, 2013; O'Hara \& Swain, 1996; Robertson, Grace, Wallington, \& Stewart, 2004,). In their review of the literature, Yim, Tanner Stapleton, Guardino, HahnHolbrook, and Dunkel Schetter (2015) highlighted the need for integrated models that systematically examine the interplay between indicators of innate risk for depression and psychosocial factors such as relationship quality. In particular, integrative models of depression during pregnancy have the potential to identify salient risk factors earlier in the perinatal period to aid in timely intervention. We now turn to a discussion of theoretical frameworks with particular relevance for understanding how intimate relationship quality intersects with innate risk to influence prenatal depression.

\section{Couple and Family Discord Model of Depression}

Originally referred to as a marital discord model (Beach, Sandeen, \& O'Leary, 1990), the couple and family discord model of depression (Beach, 2014) highlights the important role of family processes-including the intimate relationship between partners-in the development and maintenance of depression.

In particular, ample research supports robust concurrent and longitudinal associations between discord in one's intimate relationship and depression in both community and clinical samples, with meta-analyses revealing a large effect size (Whisman, 2001). Notably, this association remains significant when controlling for potential confounding factors such as gender, age, education, race, genetics, comorbid anxiety, and discord in other types of relationships (Cao, Zhou, Fang, \& Fine, 2017; Whisman, 1999; Whisman et al., 2018; Whisman, Robustelli, \& Labrecque, 2018; Whisman, Sheldon, \& Goering, 2000; Whisman, Uebelacker, \& Weinstock, 2004). Research focused on the perinatal period has also demonstrated notable links between intimate relationship discord and perinatal depression (Brock et al., 2014; Milgrom et al., 2008), underscoring the significance of examining intimate relationship processes during pregnancy.

Importantly, relationship discord only accounts for a proportion of the variance in depression. A growing body of literature points to the importance of several distinct aspects of intimate relationship functioning for explaining symptoms of depression. The bulk of these 
investigations have focused on the role of support within one's relationship (i.e., supportive responses by one's partner in the context of stress) and suggest that higher partner support predicts lower symptoms of depression (Dehle, Larsen, \& Landers, 2001), including perinatal depressive symptoms (e.g., Brock et al., 2014; Kofman et al., 2019). Inadequate partner support may reduce one's ability to cope with challenges, thus increasing one's susceptibility to symptoms of depression. Emerging evidence suggests that three additional facets of intimate relationship functioning also impact individual well-being. Specifically, research demonstrates lower rates of internalizing symptoms among individuals reporting higher closeness and intimacy in their intimate relationships (e.g., Waring, Patton, Neron, \& Linker, 1986), particularly among women (Brock \& Lawrence, 2011). Furthermore, an uneven distribution of power in one's relationship (i.e., interactions characterized by disrespect and control) is associated with higher rates of internalizing symptoms (Byrne, Carr, \& Clark, 2004; Hautzinger, Linden, \& Hoffman, 1982), particularly among men (Brock \& Lawrence, 2011). Finally, a substantial body of literature demonstrates links between sexual dysfunction and depression (Atlantis \& Sullivan, 2012), although few studies have used dyadic samples (Trudel, Villeneuve, Préville, Boyer, \& Fréchette, 2010). Considering multiple dimensions of relationship functioning is a critical step toward enhancing theoretical models explaining the role of intimate relationships in depression and improving the efficacy of relationship-based interventions for depression.

\section{A Diathesis-Stress Model of Depression}

One of the most widely cited etiological models of depression is the diathesis-stress model, which suggests that individuals possess certain innate vulnerabilities that interact with environmental factors to elicit psychological distress (Ingram \& Luxton, 2005). Within this framework, a vulnerability or "diathesis" must be activated by adverse environmental circumstances for depression to develop. The personality trait neuroticism represents a strong phenotypic expression of the diathesis for depression (Hettema, Neale, Myers, Prescott, \& Kendler, 2006). Also referred to as negative emotionality, neuroticism is defined as "individual differences in the extent to which a 
person perceives and experiences the world as threatening, problematic, and distressing" (Watson, Clark, \& Harkness, 1994, p. 26). Individuals scoring high on trait neuroticism are prone to experiencing negative emotions, self-blame, and high levels of stress. Neuroticism fits well into a diathesis-stress model given that it is relatively stable in adulthood and endogenous in nature (Clark, 2005; Ormel et al., 2013). As summarized in an extensive review and meta-analysis of the literature, there is a robust association between neuroticism and depression (Kotov, Gamez, Schmidt, \& Watson, 2010). Thus, it is not surprising that higher levels of neuroticism are also predictive of depression throughout pregnancy (Bunevicius et al., 2009).

Interpersonal factors contributing to adversity or hardship, such as discord or dysfunction in one's intimate relationship, can be conceptualized as interacting with a diathesis to elicit depression (Atkins, Dimidjian, Bedics, \& Christensen, 2009). Indeed, research has demonstrated that the effects of discordant aspects of the intimate relationship on depression are enhanced to the extent that individual partners are higher in neuroticism; however, only a few studies have demonstrated this interaction within a dyadic framework, obtaining reports from both partners (Atkins et al., 2009; Davila, Karney, Hall, \& Bradbury, 2003; Uebelacker \& Whisman, 2006). Furthermore, the aforementioned studies have (a) primarily examined global marital discord or dissatisfaction and have not examined other key dimensions of the relationship (e.g., emotional intimacy and closeness or received partner support) and (b) relied on questionnaires and confounding measures of relationship discord and depression due to subjective reporting. The use of more objective measures of relationship functioning that isolate the specific relationship processes that interact with neuroticism to predict depressive symptoms holds promise for understanding under what conditions specific dyadic behaviors increase the risk for depression in intimate partners. In addition, although research has demonstrated that psychological distress in first-time parents is associated with a poorer quality of intimate relationships and higher levels of neuroticism (Boyce, Condon, Barton, \& Corkindale, 2007), virtually no work has examined whether intimate relationship quality among pregnant couples impacts the risk for depressive symptoms differently as a function of neuroticism, with a few notable exceptions (e.g., Kofman et al., 2019). 


\section{Stress Generation Resulting From Neuroticism}

A diathesis-stress model proposes an interplay between innate characteristics and environmental factors in the development of depression; however, research also suggests that there is a direct link between diathesis and stress. Personality traits play a role in how individuals structure their lives (for a meta-analysis, see Kendler \& Baker, 2006). Higher neuroticism is associated with an increased chance of occupational and financial difficulties, less support, and more interpersonal problems (e.g., with spouses, relatives, and friends; Kendler, Gardner, \& Prescott, 2003). Neuroticism is also a robust predictor of dysfunction in intimate relationships (Caughlin, Huston, \& Houts, 2000; Karney \& Bradbury, 1995; Malouff, Thorsteinsson, Schutte, Bhullar, \& Rooke, 2010). Individuals high in neuroticism are more likely to engage in negative interactions with their partners and less likely to exhibit adaptive behaviors such as mutual problem-solving (Woszidlo \& Segrin, 2013).

This body of research is consistent with a stress generation model (Eberhart \& Hammen, 2010; Hammen, 1991), which indicates that depressed individuals generate more stress and adversity in their lives. Although research embedded within this framework often focuses on the generation of stress in response to depression, increasingly, the personality trait of neuroticism (the underlying innate vulnerability for depression) has received attention as a salient predictor of stress generation, especially with regard to the generation of negative interpersonal events (e.g., relationship conflict; Hammen, 2006; Liu \& Alloy, 2010). Thus, when considered together, stress generation and diathesis-stress models suggest a complex link between diathesis and stress, such that individuals possessing greater innate risk for depression not only require lower levels of stress to develop symptoms but also are more likely to experience stress in the first place.

\section{The Present Study}

The primary aim of the present study was to test an integrated framework guided by multiple theories of depression (i.e., stress generation, diathesis-stress, couple and family discord model) that have the 


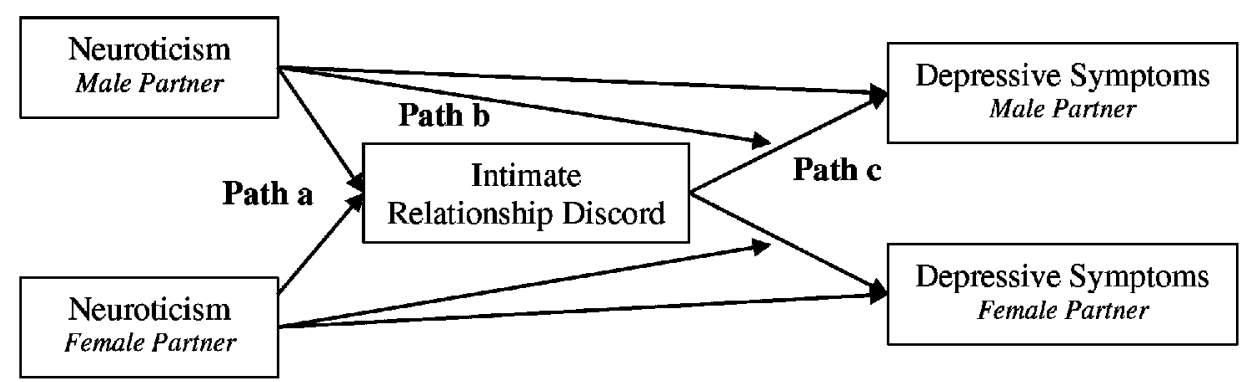

Figure 1. Stress generation is represented by Path a (higher neuroticism in either or both partners uniquely predicts intimate relationship discord), diathesis-stress is represented by Path b (interaction between neuroticism and intimate relationship discord for a given partner), and the couple and family discord model is represented by Path c (and will be conditional in the context of a significant interaction between relationship discord and neuroticism).

potential to inform our understanding of the role of intimate relationship quality in prenatal depression (see Figure 1). Specifically, within this model, intimate relationship discord contributes to depressive symptoms (couple and family discord model), and this effect is enhanced by neuroticism (diathesis-stress). Furthermore, neuroticism functions as a catalyst of the pathway that unfolds through relationship discord (stress generation) to ultimately impact depressive symptoms. To test this framework, we applied a form of moderated mediation that recognizes the dual role of neuroticism both as a catalyst of the pathway that unfolds through relationship quality to impact depression and as a modifier of the second link in this pathway (from relationship discord to depression). See Preacher, Rucker, and Hayes (2007) for a detailed description of this form of moderated mediation.

There were several innovative features of the present study. First, consistent with a multidimensional model of intimate relationship quality (Lawrence, Brock, Barry, Langer, \& Bunde, 2009), we assessed five distinct relationship processes with a semistructured clinical interview administered to both partners to examine the differential roles of unique relationship domains. These processes included (a) conflict management; (b) quality of sexuality and sensuality; (c) degree of intimacy, trust, and closeness; (d) quality of partner support received by each partner in response to stress and adversity; and (e) level of respect, acceptance, and autonomy of each individual in the relationship (see the Method section for details about the measurement of 
each domain). Based on the current literature linking several relationship processes to depression, we predicted that dysfunction in multiple areas of the relationship would emerge as predictors of prenatal depressive symptoms in the context of neuroticism.

Second, the study aims were pursued within a dyadic framework with committed, cohabiting couples navigating pregnancy. We simultaneously examined separate maternal and paternal variables within the same analysis, applying an actor-partner interdependence model (APIM) for distinguishable dyads (Kenny, Kashy, Cook, \& Simpson, 2006). This approach allowed us to investigate potential gender differences in the proposed pathways while controlling for interdependence within couples. Furthermore, by testing this model in a sample of pregnant couples, we were able to investigate the study hypotheses during a time when couples are experiencing change and adjustment in the family and are facing increased risk for depression (Grekin, Brock, \& O’Hara, 2017).

\section{Method}

\section{Participants}

Flyers and brochures were broadly distributed to businesses and clinics frequented by pregnant women. Eligibility criteria included (a) 19 years of age or older, (b) English speaking, (c) pregnant (mother) at the time of the initial appointment, (d) both partners were biological parents of the child, (e) singleton pregnancy, and (f) in a committed intimate relationship and cohabiting. A total of 162 couples enrolled. Three couples were excluded from the final sample due to invalid data or ineligibility, for a final sample of 159 heterosexual couples. The couples had dated an average of 81.90 months $(S D=49.59)$, cohabited an average of 61.00 months $(S D=41.80)$, and the majority of couples were married ( $84.9 \%$ ). Approximately $58 \%$ of couples reported that they had no children and therefore were experiencing the transition into parenthood for the first time. Most of the women were in the second $(38.4 \%)$ or third (58.5\%) trimester of pregnancy. Participants were primarily White ( $89.3 \%$ of women; $87.4 \%$ of men), and $9.4 \%$ of the women and $6.4 \%$ of the men identified as Hispanic or 
Latino. On average, the women were 28.67 years of age $(S D=4.27)$, and the men were $30.56(S D=4.52)$. The sample participants reported a median joint income of $\$ 60,000$ to $\$ 69,999$, and most of the participants were employed at least 16 hours per week $(74.2 \%$ of women; $91.8 \%$ of men). Further, the modal education was a bachelor's degree (46.5\% of women; $34.6 \%$ of men). Only five couples declined participation in the daily survey; thus, a total of 154 couples completed both the laboratory visit and the 14 days of home surveys.

\section{Procedures}

All procedures were approved by the University of Nebraska-Lincoln's institutional review board. Data collection occurred from 2016 to 2017. Both partners attended a laboratory appointment during which they completed semistructured clinical interviews. The partners were escorted to separate rooms to complete the clinical interviews and did not interact with one another until the procedures were complete. The participants were compensated with $\$ 50$ (for a total of $\$ 100$ per couple) for attending the appointment. Following the visit, the participants completed 10 to 15 minutes of questionnaires from home for 14 consecutive days, either on the internet (82\%) or by mailing a paper version. Past research demonstrates psychometric equivalence of internet and paper-and-pencil versions of couple measures (Brock, Barry, Lawrence, Dey, \& Rolffs, 2012). The partners were instructed to complete the surveys separately (alone and in private) and to record their experiences before bedtime. They were told not to complete a survey for past days and to only report on experiences that had happened on the same day as the survey. A customized checklist with the dates of each survey was provided to increase compliance. Online submissions were time stamped and closely reviewed to ensure compliance with the assessment schedule. Participants were paid up to \$50 for completing the surveys; payment was prorated based on the number of completed surveys.

\section{Measures}

Depressed mood and anhedonia. Given that lengthier daily diaries predict decreased participant compliance (Morren, Dulmen, Ouwerkerk, 
\& Bensing, 2009), we selected items that represent the core features of a major depressive episode (American Psychiatric Association, 2013). Specifically, the participants were asked to report the degree to which they had experienced the following "today" (since waking up): (1) "depressed mood (e.g., feeling sad or empty)" and (2) "diminished interest or pleasure in all, or almost all, activities.” A number of studies have supported the measurement of daily depressive symptoms using one or two face valid items based on convergent validity with established measures of depression (e.g., the Beck Depression Inventory II; Starr, 2015; Starr \& Davila, 2012a, 2012b). In the current study, if an individual endorsed experiencing both depressed mood and anhedonia on a given day, they received a score of 1 for that day (vs. o). The number of days an individual experienced both depressed mood and anhedonia represented the pervasiveness of these core features of depression for 2 weeks (prorating for missing data). Scores ranged from o to 14 (i.e., number of days when both depressive features were endorsed). The average number of days when both anhedonia and depressed mood were endorsed for men was $1.77(S D=3.18)$ and for women was $1.86(S D=$ 3.12). Nearly half of the men (42.4\%) and exactly half of the women reported at least 1 day when they experienced both anhedonia and depressed mood. There were excellent participation rates across the 14 days ( $M$ number of days surveys were completed by men was 11.76, $S D$ $=3.59$, and by women was $12.21, S D=3.05$ ).

Intimate relationship quality. The Relationship Quality Interview (RQI; Lawrence et al., 2009, 2011) is a 60- to 90-minute interview designed for interviewers to conduct functional analyses of relationships across the following multiple domains:

Conflict or problem-solving interactions: frequency and length of arguments, level and severity of negative affect, aggression or withdrawal during arguments, behaviors during arguments, recovery strategies.

Quality of sexuality and sensuality in the relationship: satisfaction with the sexual relationship, presence or absence of negative emotions during sex, sexual difficulties, sensual behaviors (e.g., cuddling). 
Emotionally intimate transactions: mutual sense of closeness, warmth, interdependence, and affection in the relationship; comfort of each partner being emotionally vulnerable; quality of selfdisclosures; friendship; demonstrations of love and affection (verbal and physical).

Received support: quality of support received in response to stress (e.g., listening, providing advice, taking care of things directly or indirectly, spending time together, boosting confidence), match between desired and received levels of support, whether support is offered in a positive or negative manner.

Received respect, acceptance, and autonomy: the extent to which the interviewed partner feels respected (i.e., treated like an equal in the relationship) and accepted (i.e., allowed to be his or her own person); partner is treated like a competent, independent adult and has decision-making power in the relationship.

The RQI assesses a dyadic level of functioning in each domain of the relationship. Open-ended questions, followed by closed-ended questions, are asked to obtain novel contextual information about functioning in the relationship during the past 6 months. Concrete behavioral indicators (e.g., "On average, how often did you and your partner argue in the last 6 months") facilitate objective ratings. As such, the RQI is not a measure of individual perceptions of relationship satisfaction (although such ratings can also be collected during the interview). Interviewers independently rated each domain on scales ranging from 1 (poor functioning) to 9 (high functioning), which were specific to functioning in each area. Interviewer ratings minimize the chance that associations between poor functioning in a key domain and other factors (e.g., depression) are due to reporting biases. Notably, the partners were interviewed separately and simultaneously to prevent response contamination; however, interviewer ratings from interviews with each partner are intended to be averaged (across raters) to obtain a dyadic-level measure of relationship functioning. The RQI has demonstrated excellent reliability, convergent validity, and divergent validity (Lawrence et al., 2009, 2011). 
Interviewers completed training in reliable coding of the RQI and participated in consensus and recalibration meetings throughout the course of the assessment period to ensure reliable coding. A different research assistant coded each partner, and the coders were instructed not to discuss interviews from the same couple to ensure maximum objectivity. Approximately 20\% of the maternal and paternal interviews were randomly assigned and double coded to assess interrater reliability, which was excellent (average intraclass correlation coefficient $=.91$ ).

Correlations between scores from maternal and paternal interviews were significant for trust $(r=.26, p=.001)$, sex $(r=.53, p<.001)$, and conflict ( $r=.51, p<.001$ ) and, as is customary with the RQI (Lawrence et al., 2009, 2011), maternal and paternal interview scores were averaged to create dyadic scores. Notably, this approach to aggregating correlated scores from multiple informants is advantageous for several reasons, including the ability to capture unique perspectives of what is unfolding in the relationship while retaining variance that can be attributed to shared experiences and producing less biased and more reliable estimates of the constructs (Lengua et al., 2008). Nonetheless, in this sample of pregnant couples, interpartner correlations were relatively small for respect $(r=.18, p=.021)$ and support $(r=.11, p$ $=.161$ ). Closer examination of mean differences in scores from interviews with each partner revealed that, on average, pregnant mothers received more respect and acceptance from their partners (relative to fathers), $t(158)=2.78, p=.006$, whereas fathers received more support from their partners (relative to mothers), $t(158)=2.05, p=$ .042. Because of gender differences in this sample of pregnant couples and the small correlations between objective ratings from interviews with each partner, we examined separate partner scores of respect and support.

Neuroticism. The General Temperament Survey (Clark \& Watson, 1990) is a self-report inventory designed to assess the three core temperament dimensions. The General Temperament Survey is based on the Schedule for Nonadaptive and Adaptive Personality-2nd Edition (Clark, Simms, Wu, \& Casillas, 2014), and each scale has demonstrated good internal consistency, discriminant validity, and test-retest reliability across multiple samples. The measure has a true-or-false 
response format. The Negative Temperament (i.e., neuroticism) scale comprises 28 items and had excellent internal consistency in this sample (Cronbach's $\alpha=.91$ ). Individuals scoring high on this scale are prone to frequent and intense negative emotions, often worry, feel discomfort in a wide range of situations, and portray the world in a negative light.

Potential covariates. Several demographic variables (e.g., annual joint income, employment status, age) and family characteristics (e.g., marital status, week of pregnancy, first-time parenthood) were examined, but only annual joint income emerged as an important covariate. Specifically, couples with lower joint incomes had worse conflict management ( $r=.20, p=.013$ ) and more depressive symptoms reported by men $(r=-.20, p=.016)$.

\section{Data Analytic Plan}

Data were analyzed using Mplus software (Muthén \& Muthén, 2010). Multiple indices were used to assess global model fit. We report the comparative fit index (Bentler, 1990), the root mean square error of approximation (Browne \& Cudeck, 1992), and the standard root mean residual (Hu \& Bentler, 1995). For the comparative fit index, values of .90 or greater reflect adequate fit of the model. For the root mean square error of approximation and standard root mean residual, values lower than 0.10 indicate adequate fit (MacCallum, Browne, \& Sugawara, 1996). Missing data were minimal (covariance coverage ranged from 0.97 to 1.00) and were addressed with full information maximum likelihood estimation. To account for violations of normality, we used maximum likelihood estimation with robust standard errors (MLR). Nonetheless, across the study variables, estimates of skewness (range -1.08 to 2.33 ) and kurtosis (range -0.12 to 5.23 ) were relatively small.

Analyses were conducted using APIM for distinguishable dyads (Kenny et al., 2006) such that the couple was the unit of analysis. In the basic APIM, there are two dyad members, two variables ( $X$ and $Y$ ) for each member, and the following two sets of effects: (a) $X$ affects own $Y$ (actor effects) and (b) $X$ affects partner's $Y$ (partner effects). In the case of distinguishable dyads, there are two actor effects (e.g., 
Male $X_{1} \rightarrow$ Male $Y_{1}$, Female $X_{2} \rightarrow$ Female $Y_{2}$ ) and two partner effects (e.g., Male $X_{1} \rightarrow$ Female $Y_{2}$, Female $X_{2} \rightarrow$ Male $Y_{1}$ ). The implementation of partner effects allows for the estimation of relational effects as opposed to focusing only on intrapersonal (actor) effects that can be overestimated when examined alone. There are two correlations in the model between the (a) exogenous variables $\left(X_{1}\right.$ and $\left.X_{2}\right)$ and (b) residuals of the endogenous variables $\left(Y_{1}\right.$ and $\left.Y_{2}\right)$.

A moderated mediation model was tested (Preacher et al., 2007), which involves the predictor (neuroticism) triggering a mediation pathway, but also functioning as a moderator of the second path (from relationship distress to depressive symptoms). We performed a nonparametric resampling method (bias-corrected bootstrap) with 5,000 resamples drawn to derive the 95\% confidence interval (CI) for the indirect effects (Preacher et al., 2007). The model was expanded to incorporate key features of APIM as previously described. Notably, for three of the models, the mediators trust, sex, and conflict were dyadic scores (not separate partner scores), thus simplifying the nature of the models relative to those focused on received support and received respect.

\section{Results}

Descriptive statistics and correlations are reported in Table 1. One's own neuroticism was moderately associated with one's own depressive symptoms. Maternal neuroticism was related to all relationship domains except sexual quality. Paternal neuroticism was associated with the majority of relationship domains except sexual quality, support received by women, and respect toward women. There were significant bivariate associations between paternal depressive symptoms and (low) sexual quality, intimacy, support received by men, and respect toward men. Only conflict had a significant bivariate association with maternal depressive symptoms.

\section{Testing the Integrated Model}

The results from the final integrated models (Figure 1) are reported in Table 2 for conflict, sex, and trust (dyadic scores), and in Table 3 they are reported for received support and received respect. There 


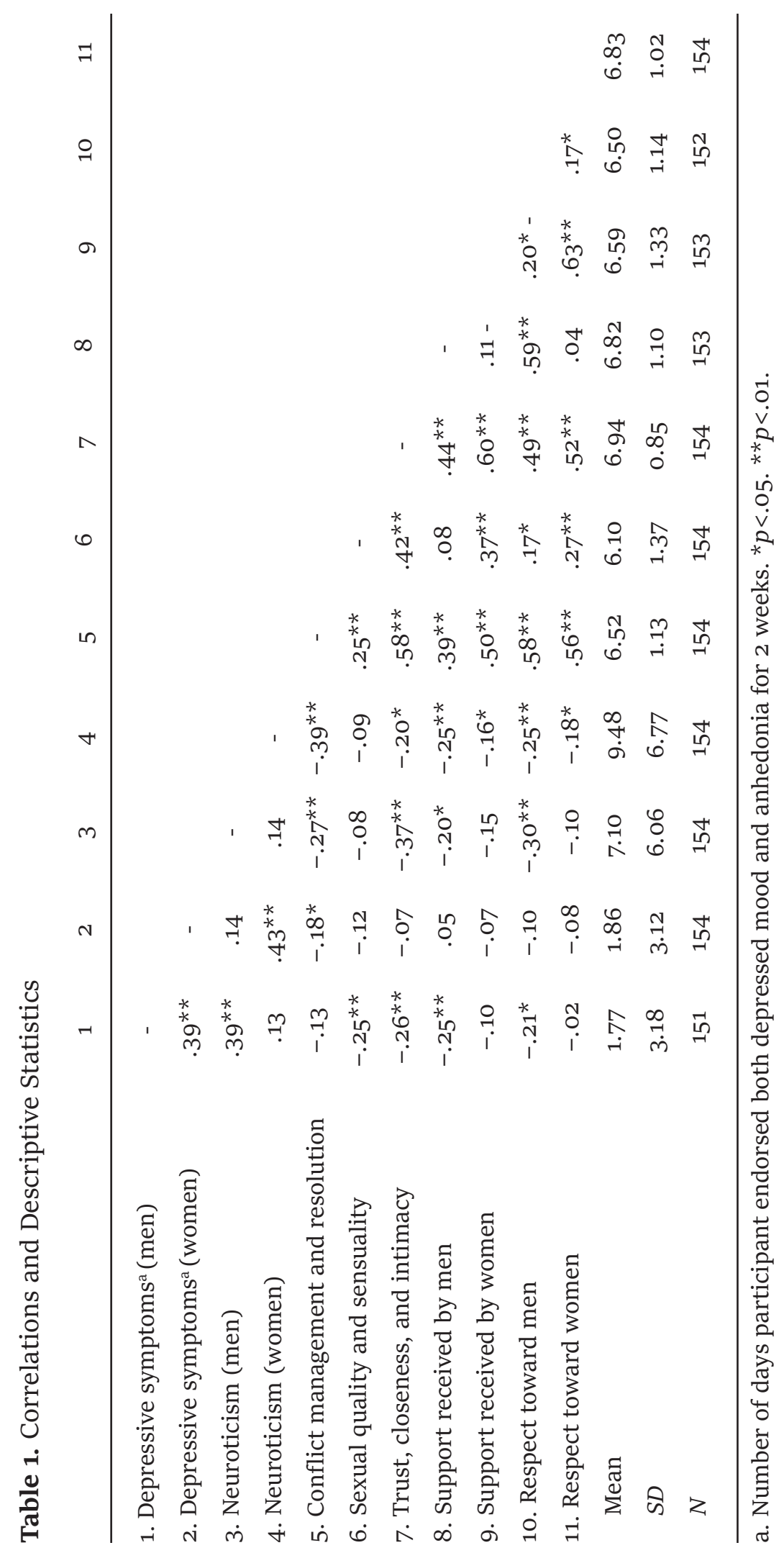


Table 2. Final Results of Each Model for Couple-Level RQI Domains

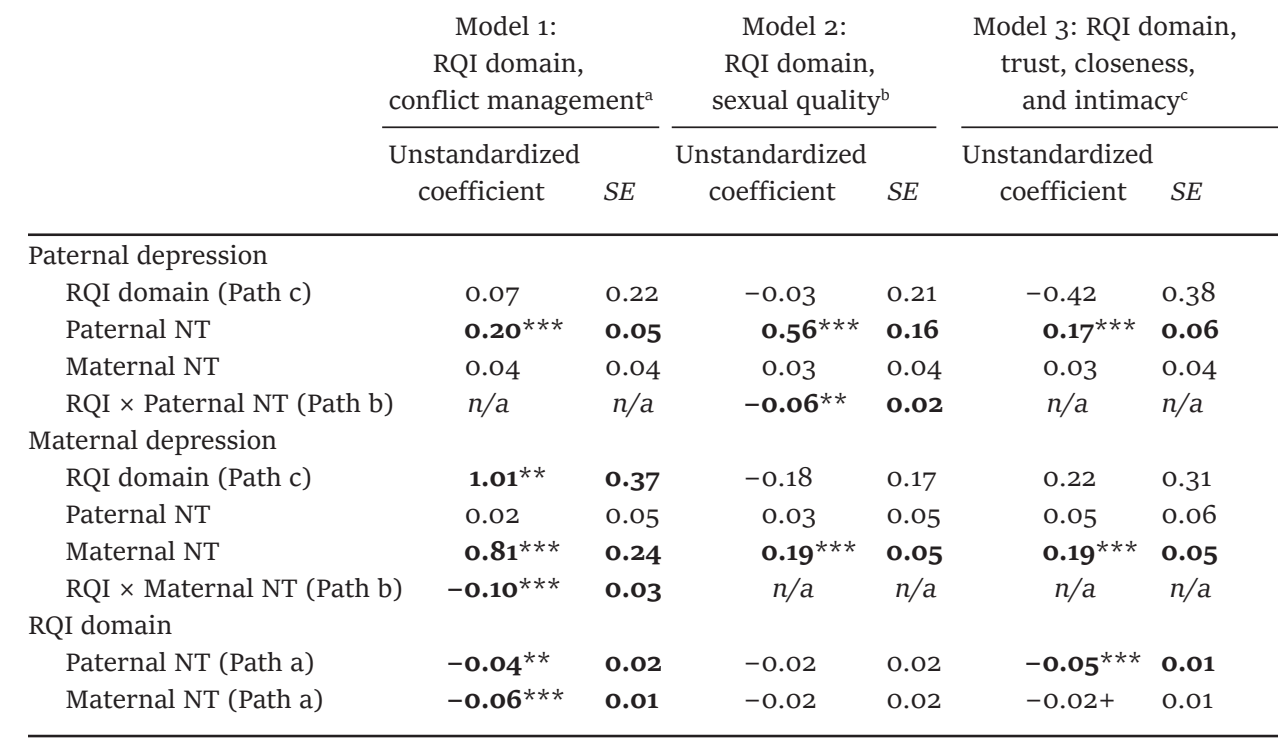

Annual joint income was controlled for in the analyses.

Bolded values were significant at $p<.05$.

$n / a=$ preliminary analyses revealed a nonsignificant interaction and, accordingly, the interaction was omitted from the final model; NT = neuroticism; RQI = Relationship Quality Interview.

a. Comparative fit index $=.983$; root mean square error of approximation $=0.065$; standard root mean residual $=.050$.

b. Comparative fit index $=.974$; root mean square error of approximation $=0.072$; standard root mean residual $=.044$.

c. Comparative fit index $=.964$; root mean square error of approximation $=0.075$; standard root mean residual $=.050$.

${ }^{* *} p<.01 ; * * * p<.005 ;+p<.10$

was evidence of moderated mediation in two of the five tested models. First, maternal neuroticism was associated with (poor) conflict management that in turn was associated with maternal depressive symptoms, and this indirect pathway was stronger under higher levels of maternal neuroticism. The indirect effect of maternal neuroticism on maternal depressive symptoms via conflict was present for women with neuroticism scores $\geq 16.30$ (1.01 $S D$ above the mean), $b=0.04,95 \%$ CI [0.00008-0.08261]. In addition, at low levels of neuroticism ( $<5.90,0.53 S D$ below the mean), there was a reverse effect such that higher levels of maternal neuroticism were actually associated with less maternal depressive symptoms, $b=-0.03,95 \%$ CI [-0.07225 to -0.00007$]$. We return to this surprising finding in the Discussion section. Please refer to Figure 2 for a graphical depiction of the results. 
Table 3. Final Results of Each Model for Partner (Received) RQI Domains

\begin{tabular}{|c|c|c|c|c|}
\hline & \multicolumn{2}{|c|}{$\begin{array}{l}\text { Model 1: RQI domain, } \\
\text { received support }\end{array}$} & \multicolumn{2}{|c|}{$\begin{array}{l}\text { Model 2: RQI domain, } \\
\text { received respect }{ }^{\mathrm{b}}\end{array}$} \\
\hline & $\begin{array}{l}\text { Unstandardized } \\
\text { coefficient }\end{array}$ & $S E$ & $\begin{array}{l}\text { Unstandardized } \\
\text { coefficient }\end{array}$ & $S E$ \\
\hline \multicolumn{5}{|l|}{ Paternal depression } \\
\hline Received by dad (RQI; Path c) & 0.03 & 0.26 & -0.24 & 0.26 \\
\hline Received by mom (RQI; Path c) & 0.00 & 0.21 & 0.16 & 0.22 \\
\hline Paternal NT & $0.58^{*}$ & 0.23 & $0.19 * * *$ & 0.05 \\
\hline Maternal NT & 0.01 & 0.05 & 0.03 & 0.04 \\
\hline RQI × Paternal NT (Path b) & $-0.06+$ & 0.03 & $n / a$ & $n / a$ \\
\hline \multicolumn{5}{|l|}{ Maternal depression } \\
\hline Received by dad (RQI; Path c) & $0.55^{* * *}$ & 0.18 & 0.07 & 0.20 \\
\hline Received by mom (RQI; Path c) & 0.00 & 0.22 & $0.63+$ & 0.34 \\
\hline Paternal NT & 0.05 & 0.05 & 0.04 & 0.05 \\
\hline Maternal NT & $0.21^{* * *}$ & 0.05 & $0.59 *$ & 0.26 \\
\hline RQI × Maternal NT (Path b) & $n / a$ & $n / a$ & $-0.06+$ & 0.03 \\
\hline \multicolumn{5}{|l|}{ Received by dad (RQI) } \\
\hline Paternal NT (Path a) & $-0.03+$ & 0.02 & $-0.05^{\star * *}$ & 0.02 \\
\hline Maternal NT (Path a) & $-0.04^{* * *}$ & 0.01 & $-0.04^{* * *}$ & 0.01 \\
\hline \multicolumn{5}{|l|}{ Received by mom (RQI) } \\
\hline Paternal NT (Path a) & -0.03 & 0.02 & -0.01 & 0.01 \\
\hline Maternal NT (Path a) & $-0.03+$ & 0.02 & $-0.03^{*}$ & 0.01 \\
\hline
\end{tabular}

Annual joint income was controlled for in the analyses.

Bolded values were significant at $p<.05$.

$n / a=$ preliminary analyses revealed a nonsignificant interaction $(p>.10)$ and, accordingly, the interaction was omitted from the final model; NT = neuroticism; RQI = Relationship Quality Interview.

a. Comparative fit index $=.981$; root mean square error of approximation $=0.053$; standard root mean residual $=.040$.

b. Comparative fit index $=.981$; root mean square error of approximation $=0.058$; standard root mean residual $=.045$

${ }^{*} p<.05 ; * * * p<.005 ;+p<.10$

Second, paternal and maternal neuroticism were both uniquely associated with (poor) quality support received by men that, in turn, was associated with paternal depressive symptoms. Paternal neuroticism indirectly influenced paternal symptoms by undermining the quality of support received by men, and this indirect effect was present for men who had approximately average levels of neuroticism (6.70, which is 0.06 SDs below the mean, $b=0.01$, 95\% CI [0.000010.04064]) or higher. Please refer to Figure 3.

Because neuroticism was not associated with sexual quality, the hypothesized model was not supported for sexual quality; however, there was a significant interaction between sexual quality and neuroticism. Closer examination revealed that poor sexual quality was associated with higher paternal depressive symptoms for men with approximately average levels of neuroticism (5.10, which is $0.33 \mathrm{SD}$ below the mean), $b=-0.35,95 \%$ CI $[-0.690$ to -0.004$]$ ) or higher. 


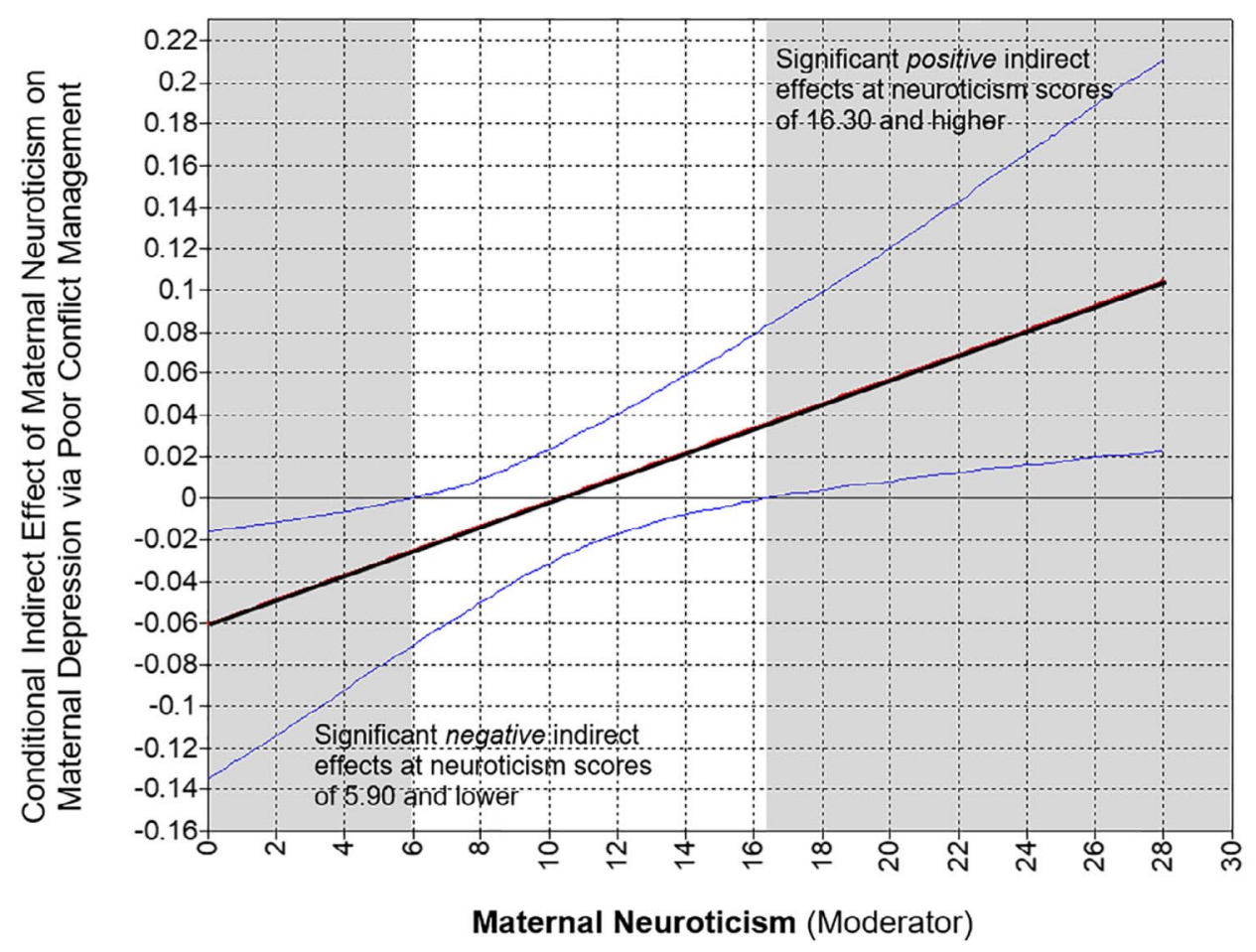

Figure 2. The graph contains conditional indirect effects of maternal neuroticism on maternal depressive symptoms via poor conflict management ( $y$ axis) at different levels of neuroticism ( $x$ axis) with 95\% confidence intervals around estimates of indirect effects. Regions of significance are shaded. At neuroticism scores of 16.30 (1.01 $S D$ above the mean) and higher, more neuroticism was associated with more depressive symptoms through impaired conflict management. At low levels of neuroticism (scores of 5.90 and lower; $0.53 S D$ below the mean), less neuroticism was associated with better conflict management (e.g., fewer arguments) that, contrary to expectations, was associated with a greater risk for depressive symptoms.

\section{Discussion}

The primary aim of the present study was to test an integrated framework guided by multiple theories of depression with relevance for understanding the role of intimate relationship quality in prenatal depression. In a sample of couples navigating pregnancy, a time of elevated risk for depression and relationship dysfunction (Gaynes et al., 2005), we investigated five dimensions of intimate relationship quality. We found support for the complete, integrated model for the two most widely investigated dimensions of intimate relationship qualityconflict management and partner support (Brock, Kroska, \& Lawrence, 


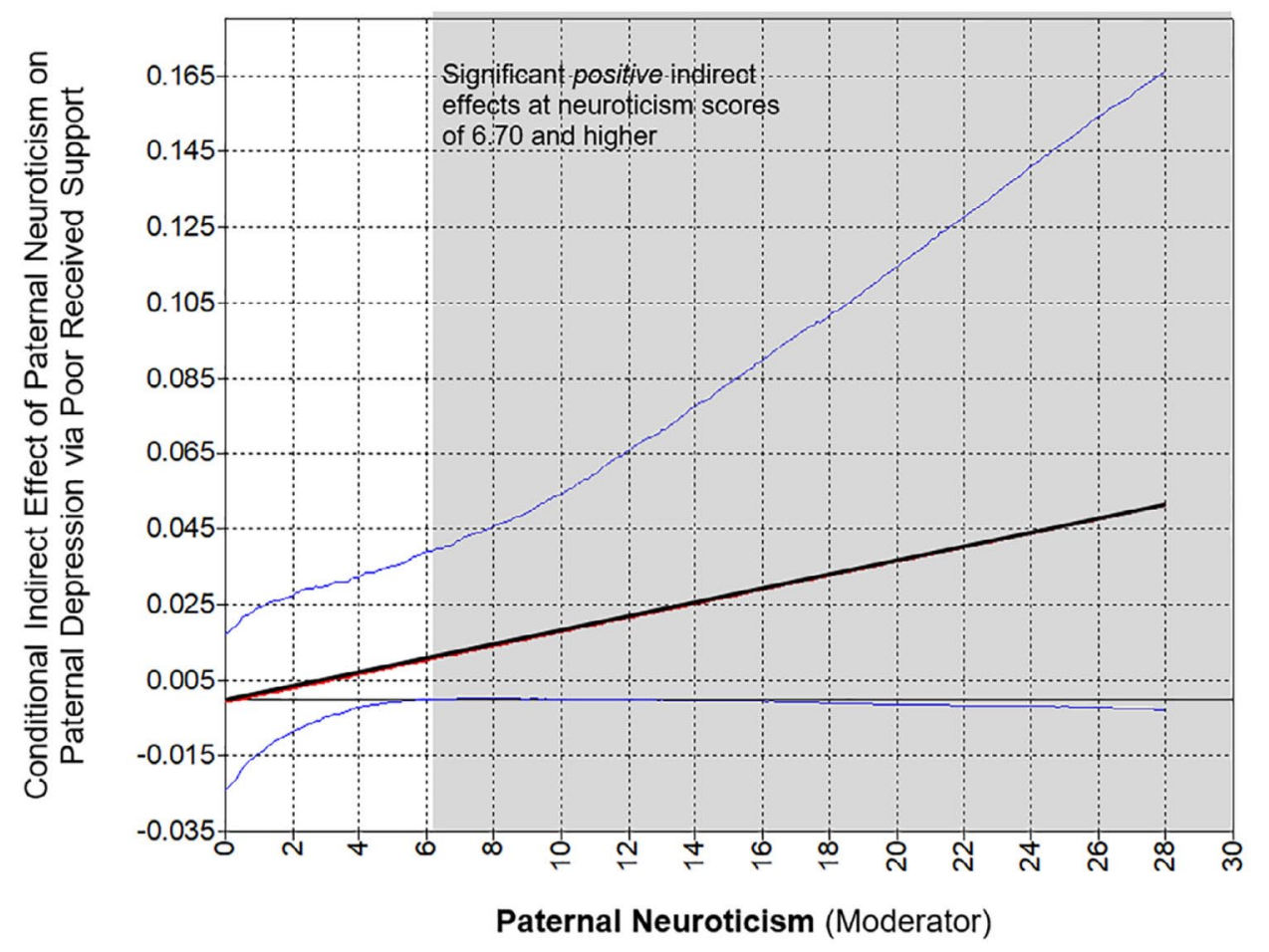

Figure 3. This graph contains conditional indirect effects of paternal neuroticism on paternal depressive symptoms via poor support ( $y$ axis) at various levels of neuroticism ( $x$ axis) with 95\% confidence intervals around estimates of indirect effects. At neuroticism scores of 6.70 (o.06 SD below the mean) and higher, more neuroticism was significantly associated with more depressive symptoms through deceased quality of support available to men. This effect grew in magnitude as neuroticism scores increased.

2016). For women, higher levels of neuroticism predicted worse conflict management that, in turn, was associated with higher levels of maternal depressive symptoms; however, this pathway was only present for women with above average levels of neuroticism. For men, higher levels of neuroticism predicted poorer support quality received by men that, in turn, was associated with higher levels of paternal depressive symptoms; this pathway was present for men of average neuroticism and higher. Notably, a partner path emerged suggesting that maternal neuroticism also contributes to this process by further undermining the quality of support available to men.

Taken together, the results suggest that neuroticism might pose dual risk for depressive symptoms when examined within an interpersonal framework, such that it not only generates interpersonal 
stress in the form of poor conflict management and poor partner support but also enhances the deleterious effects of these forms of interpersonal stress. Furthermore, within the support model, women also reported more pervasive depressive symptoms if their partners had access to better support, controlling for neuroticism. Perhaps these women are prioritizing their partners' needs above their own selfcare and in turn are undermining their own emotional health. How support processes unfold for couples during pregnancy appears to be a complex phenomenon warranting closer attention. Indeed, the results suggest that broadly promoting support in the relationship, without consideration of balancing the needs of each partner, might be counterproductive.

Interestingly, there was an unexpected finding for women who were very low in neuroticism. Specifically, women experienced more depressed mood and anhedonia to the extent that conflict management was better in the relationship. That is, toward the lower end of the distribution of neuroticism scores, women no longer seemed to benefit from good conflict management in the relationship. In fact, better conflict management seemed to enhance the risk for depressive symptoms among individuals with increasingly low levels of neuroticism. Of note, high scores on the conflict management and resolution domain of the RQI could simply reflect the fact that couples rarely argue and as such appear to be high functioning despite the potential for unresolved points of contention in the relationship. Accordingly, it is possible that women who were very low in neuroticism and did not have sufficient opportunities to work through areas of disagreement in their relationships might be at elevated risk for depressive symptoms. Given the novelty of this finding, it should be interpreted with caution, and replication is required. Nonetheless, emerging research points toward a curvilinear effect of neuroticism such that negative outcomes have been observed at both high and very low levels of neuroticism (e.g., Daspe, Sabourin, Péloquin, Lussier, \& Wright, 2013; Mullins-Sweatt \& Widiger, 2006).

The vast majority of research linking couple relationships to depression has focused on conflict and discord or (poor) partner support. Yet based on emerging research linking additional relational processes to depression risk (e.g., Brock \& Lawrence, 2011; Byrne et al., 2004; Barry, Bunde, Brock, \& Lawrence, 2009; Trudel et al., 2010), we tested our 
hypothesized framework with additional indicators of relationship quality, including intimacy, quality of the sexual relationship, and degree of respect and autonomy provided to each partner. Despite a lack of evidence for the full, integrated framework when examining these relationship dimensions, the quality of the sexual relationship emerged as a significant predictor of depression for men who were of average (or higher) neuroticism. Consistent with prior evidence of a robust link between sexual dysfunction and depression (for a review, see Atlantis \& Sullivan, 2012), men experienced more pervasive depressed mood and anhedonia over 2 weeks to the extent that the relationship was characterized by infrequent sex, broadly defined (not limited to intercourse), unsatisfying sexual encounters (e.g., negative emotions or not enjoying sex), sexual dysfunction, or infrequent sensual behaviors (e.g., touching, cuddling). Furthermore, this effect was enhanced to the extent that men were higher in neuroticism, suggesting neuroticism intensified the effects of a poor-quality sexual relationship on men's well-being. Interestingly, sexual quality was the only relationship domain that was not associated with either partner's neuroticism.

When controlling for neuroticism, neither maternal nor paternal depressive symptoms were predicted by (a) the quality of intimacy in the relationship or (b) the degree to which partners were respected and accepted and had the freedom to pursue individual pursuits. This contradicts past research suggesting that trust has long-term implications for women's mental health and that respect and autonomy are important for the mental health of men (Brock \& Lawrence, 2011). Inconsistent findings might reflect the differential importance of certain relationship dimensions at different stages of the relationship (e.g., Brock \& Lawrence [2011] assessed depression during the first 7 years of marriage), or this could be an artifact of examining more immediate consequences of relationship dysfunction (i.e., during the 2 weeks following the interview) rather than long-term trajectories. It is notable that there was a significant negative association between intimacy and paternal depressive symptoms, but this effect was no longer significant when controlling for neuroticism. Thus, perhaps it is the shared, overlapping variance between neuroticism and (low) intimacy that explains variability in paternal symptoms. Future research is needed to better understand the role of trust, closeness, and intimacy in the developmental course of depression. 


\section{Theoretical, Empirical, and Clinical Implications}

Before turning to implications, there were several limitations to the present study that should be considered when interpreting the results. First, although our daily diary approach allowed for an ecologically valid measure of the two core features of depression (i.e., depressed mood and anhedonia), due to the brevity of the daily survey (to minimize participant burden), we did not assess the full range of depressive symptoms. Rather, we focused on the two core features of depression required for a diagnosis of major depressive disorderdepressed mood and anhedonia-and the pervasiveness of those cooccurring symptoms over 2 weeks. Thus, it is unclear if individuals met full diagnostic criteria for a major depressive disorder, and our community sample would likely yield a smaller proportion of participants with clinically significant levels of depression than clinical samples. Second, although there was temporal precedence of intimate relationship quality relative to assessment of depressive symptoms, the long-term effects of relationship quality as a function of neuroticism remain unclear. The next step in this line of research will be to apply the integrated model to examine the role of neuroticism in predicting longitudinal trajectories of relationship dysfunction and depressive symptoms. Third, the sample was composed of heterosexual, cohabiting couples who were largely White and from a middle-class background, which limits the generalizability of the results; research investigating similar processes in sexual minority couples and ethnically and racially diverse, lower income couples is warranted. Fourth, although the use of semistructured interviews to assess relationship quality has numerous strengths (e.g., interviewers make objective ratings), it is important to acknowledge that ratings are based on partner reports of interactions in the relationship. Direct, behavioral observation measures might yield different findings. In addition, we largely measured dyadic processes within the relationship; examining the unique experiences of each partner in the relationship, including discrepant perceptions of relationship functioning, might reveal unique risk factors for depression. Finally, it is important to note the reciprocal association between relationship quality and depression (Davila et al., 2003). The tested model did not account for the reverse pathway from depression to relationship quality. As such, future research 
should implement long-term longitudinal designs to examine the bidirectional association that unfolds between relationship quality and depression in the context of innate risk.

The results of the present study exemplify how couple researchers might benefit from routinely considering the innate vulnerabilities of each partner that not only increase the risk for relationship dysfunction but also enhance the effects of dysfunction on depression (posing dual risk). Indeed, in an article revisiting the couple and family discord model (Beach, 2014), genetic moderation was explored as a new direction. Considering biobehavioral and genetic indicators of risk might facilitate the identification of interpersonal pathways contributing to depression. In addition, the results suggest that research embedded within a diathesis-stress framework might benefit from routinely considering how interpersonal stressors-including relationship dysfunction for individuals in committed, intimate relationships-interact with one's innate risk for depression. This unified approach to studying depression risk has the potential to delineate the complex interplay among a range of intrapersonal and interpersonal risk factors ultimately contributing to depression.

Our findings extend past research demonstrating interactions between neuroticism and subjective reports of relationship discord (Davila et al., 2003; Uebelacker \& Whisman, 2006) by incorporating relatively objective indices of relationship functioning across multiple domains using a semistructured clinical interview with strong psychometric properties. As such, we were able to isolate specific behaviors unfolding in the couple relationship that ultimately contribute to the risk for prenatal depression in both partners. For example, lower quality conflict management was operationalized as more frequent arguments, negative affect expressed during disagreements, the presence of psychological or physical abuse, and lingering tension in the relationship following arguments. The results indicate that poor conflict management, defined in this way, has the potential to escalate interpersonal stress that in turn interacts with the underlying diathesis for depression (i.e., neuroticism) for women. Furthermore, the extent to which poor quality partner support was provided to men in response to stress and adversity (i.e., support was provided in an unskillful manner, support did not serve coping efforts), men with average or higher levels of neuroticism were at an elevated risk for depression. 
In addition, sexual quality tends to be overlooked in couples research as a relationship dimension influencing mental health. Yet the results of the present study suggest that this might be an important aspect of couple functioning for men's mental health, especially to the extent that men are higher in neuroticism.

With regard to clinical implications, the results support recent practice recommendations to more routinely include partners in individual treatment for depression and other comorbid forms of psychopathology (Whisman \& Baucom, 2012). It is notable that, in the present study, several dimensions of the intimate relationship uniquely predicted the pervasiveness of depressive symptoms over 2 weeks for both men and women when controlling for neuroticism, demonstrating the incremental predictive utility of relationship dysfunction. Clinicians treating depressed patients might benefit from comprehensively assessing multiple features of the intimate relationship and considering strengths of the relationship that might scaffold the therapeutic process as well as areas of dysfunction that might undermine progress. Obstetricians and other practitioners routinely working with perinatal women might also consider the larger family context and the role that one's partner might play in maternal health.

\section{Conclusion}

In the present study, we integrated several theoretical frameworks (i.e., diathesis-stress, stress generation, couple and family discord model) to understand how intimate relationships contribute to the risk for both maternal and paternal depression during pregnancy. The most compelling support for the hypothesized, integrated model was found for intimate relationship processes either functioning as interpersonal stressors (i.e., poor conflict management for women) or serving a primary role in managing stress (i.e., received support in response to stress for men). This pattern of results is consistent with conceptual frameworks of interpersonal dysfunction as a form of stress interacting with one's diathesis (Atkins et al., 2009). In both cases, neuroticism appeared to pose a dual risk for developing depressive symptoms, such that it (a) contributed to greater interpersonal stress or depleted an individual's resources for coping with stress 
(poor support) and (b) enhanced the deleterious effects of intimate relationship dysfunction on depressive symptoms. Our integrated relational framework of depression suggests a need for future research incorporating measurement of both neuroticism (diathesis) and multiple dimensions of the intimate relationship (interpersonal stress) to better illuminate the development of depressive symptoms during pregnancy and the postpartum period.

Acknowledgments This research was funded by several internal funding mechanisms awarded to Rebecca Brock (principal investigator) from the University of Nebraska-Lincoln's Department of Psychology, the Nebraska Tobacco Settlement Biomedical Research Development Fund, and the University of Nebraska-Lincoln's Office of Research and Economic Development. We thank the families who participated in this research and the entire team of research assistants who contributed to various stages of the study. In particular, we thank Jennifer Blake and Kailee Groshans for project coordination and Tess Barnes and Cody Meyer for assistance with manuscript preparation.

\section{References}

American Psychiatric Association. (2013). Diagnostic and statistical manual of mental disorders (5th ed.). Washington, DC: APA. https://doi.org/10.1176/appi. books.9780890425596.744053

Atkins, D. C., Dimidjian, S., Bedics, J. D., \& Christensen, A. (2009). Couple discord and depression in couples during couple therapy and in depressed individuals during depression treatment. Journal of Consulting and Clinical Psychology, 77, 1089-1099. https://doi.org/10.1037/a0017119

Atlantis, E., \& Sullivan, T. (2012). Bidirectional association between depression and sexual dysfunction: A systematic review and metaanalysis. The Journal of Sexual Medicine, 9, 1497-1507. https://doi. org/10.1111/j.1743-6109.2012.02709.X

Beach, S. R. H. (2014). A couple and family discord model of depression: Updates and future directions. In C. R. Agnew \& S. C. South (Eds.), Interpersonal relationships and health: Social and clinical psychological mechanisms (pp. 133155). New York, NY: Oxford.

Beach, S. R. H., Sandeen, E. E., \& O'Leary, K. D. (1990). Depression in marriage: A model for etiology and treatment. New York, NY: Guilford.

Bentler, P. M. (1990). Comparative fit indexes in structural models. Psychological Bulletin, 107, 238-246. https://doi.org/10.1037/0033-2909.107.2.238 
Boyce, P., Condon, J., Barton, J., \& Corkindale, C. (2007). First-time fathers study: Psychological distress in expectant fathers during pregnancy. Australian and New Zealand Journal of Psychiatry, 41, 718-725. https://doi. org/10.1080/00048670701517959

Brock, R. L., Barry, R. A., Lawrence, E., Dey, J., \& Rolffs, J. (2012). Internet administration of paper-and-pencil questionnaires used in couple research: Assessing psychometric equivalence. Assessment, 19, 226-242. https://doi. org/10.1177/1073191110382850

Brock, R. L., Kroska, E., \& Lawrence, E. (2016). Current status of research on couples. In T. Sexton \& J. Lebow (Eds.), Handbook of family therapy (pp. 409433). New York, NY: Taylor \& Francis.

Brock, R. L., \& Lawrence, E. (2011). Marriage as a risk factor for internalizing disorders: Clarifying scope and specificity. Journal of Consulting and Clinical Psychology, 79, 577-589. https://doi.org/10.1037/aoo24941

Brock, R. L., O’Hara, M. W., Hart, K. J., McCabe, J. E., Williamson, J. a. A., Laplante, D. P., ... King, S. (2014). Partner support and maternal depression in the context of the Iowa floods. Journal of Family Psychology, 28, 832-843. https:// doi.org/10.1037/famoo00027

Browne, M. W., \& Cudeck, R. (1992). Alternative ways of assessing model fit. Sociological Methods \& Research, 21, 230-258. https://doi.org/10.1177/004912 4192021002005

Bunevicius, R., Kusminskas, L., Bunevicius, A., Nadisauskiene, R. J., Jureniene, K., \& Pop, V. J. M. (2009). Psychosocial risk factors for depression during pregnancy. Acta Obstetricia et Gynecologica Scandinavica, 88, 599-605. https://doi.org/10.1080/00016340902846049

Byrne, M., Carr, A., \& Clark, M. (2004). Power in relationships of women with depression. Journal of Family Therapy, 26, 407-429. https://doi. org/10.1111/j.1467-6427.2004.00291.X

Cao, H., Zhou, N., Fang, X., \& Fine, M. (2017).Marital well-being and depression in Chinese marriage: Going beyond satisfaction and ruling out critical confounders. Journal of Family Psychology, 31, 775-784. https://doi. org/10.1037/famooo0312

Caughlin, J. P., Huston, T. L., \& Houts, R. M. (2000). How does personality matter in marriage? An examination of trait anxiety, interpersonal negativity, and marital satisfaction. Journal of Personality and Social Psychology, 78, 326-336. https://doi.org/10.1037//0022-3514.78.2.326

Clark, L. A. (2005). Temperament as a unifying basis for personality and psychopathology. Journal of Abnormal Psychology, 114, 505-521. https://doi. org/10.1037/0021-843X.114.4.505

Clark, L. A., Simms, L. J., Wu, K. D., \& Casillas, A. (2014). Schedule for nonadaptive and adaptive personality (2nd ed.). South Bend, IN: University of Notre Dame.

Clark, L. A., \& Watson, D. (1990). The general temperament survey (GTS) (Unpublished manuscript). Notre Dame, IN: Department of Psychology, University of Notre Dame. 
Daspe, M., Sabourin, S., Péloquin, K., Lussier, Y., \& Wright, J. (2013). Curvilinear associations between neuroticism and dyadic adjustment in treatment-seeking couples. Journal of Family Psychology, 27, 232-241. https://doi.org/10.1037/ $\underline{\mathrm{a} 0032107}$

Davila, J., Karney, B. R., Hall, T. W., \& Bradbury, T. N. (2003). Depressive symptoms and marital satisfaction: Within-subject associations and the moderating effects of gender and neuroticism. Journal of Family Psychology, 17, 557-570. https://doi.org/10.1037/0893-3200.17.4.557

Dehle, C., Larsen, D., \& Landers, J. E. J. (2001). Social support in marriage. American Journal of Family Therapy, 29, 307-324. https://doi. org/10.1080/01926180126500

Eberhart, N. K., \& Hammen, C. L. (2010). Interpersonal style, stress, and depression: An examination of transactional and diathesis-stress models. Journal of Social and Clinical Psychology, 29, 23-38. https://doi.org/10.1521/ jscp.2010.29.1.23

Gaynes, B. N., Gavin, N., Meltzer-Brody, S., Lohr, K. N., Swinson, T., Gartlehner, G., ... Miller, W. C. (2005). Perinatal depression: Prevalence, screening accuracy and screening outcomes. Rockville, MD: Agency for Healthcare Research and Quality.

Grekin, R., Brock, R. L., \& O’Hara, M. W. (2017). The effects of trauma on perinatal depression: Examining trajectories of depression from pregnancy through 24 months postpartum in an at-risk population. Journal of Affective Disorders, 218, 269-276. https://doi.org/10.1016/j.jad.2017.04.051

Hammen, C. (2006). Stress generation in depression: Reflections on origins, research, and future directions. Journal of Clinical Psychology, 62, 1065-1082. https://doi.org/10.1002/jclp.20293

Hammen, C. L. (1991). Generation of stress in the course of unipolar depression. Journal of Abnormal Psychology, 100, 555-561.

Hautzinger, M., Linden, M., \& Hoffman, N. (1982). Distressed couples with and without a depressed partner: An analysis of their verbal interaction. Journal of Behavior Therapy and Experimental Psychiatry, 13, 307-314. https://doi. org/10.1016/0005-7916(82)90075-1

Hettema, J. M., Neale, M. C., Myers, J. M., Prescott, C. A., \& Kendler, K. S. (2006). A population-based twin study of the relationship between neuroticism and internalizing disorders. The American Journal of Psychiatry, 163, 857-864. https://doi.org/10.1176/ajp.2006.163.5.857

Hu, L., \& Bentler, P. M. (1995). Evaluating model fit. In R. H. Hoyle (Ed.), Structural equation modeling: Concepts, issues, and applications (pp. 76-99). Thousand Oaks, CA: SAGE.

Ingram, R. E., \& Luxton, D. D. (2005). Vulnerability-stress models. In B. L. Hankin \& J. R. Z. Abela (Eds.), Development of psychopathology: A vulnerability-stress perspective (pp. 32-46). Thousand Oaks, CA: SAGE.

Karney, B. R., \& Bradbury, T. N. (1995). The longitudinal course of marital quality and stability: A review of theory, method, and research. Psychological Bulletin, 118, 3-34. https://doi.org/10.1037/0033-2909.118.1.3 
Kendler, K. S., \& Baker, J. H. (2006). Genetic influences on measures of the environment: A systematic review. Psychological Medicine, 37, 615-626. https://doi.org/10.1017/So033291706009524

Kendler, K. S., Gardner, C. O., \& Prescott, C. A. (2003). Personality and the experience of environmental adversity. Psychological Medicine, 33, 1193-1202. https://doi.org/10.1017/So033291703008298

Kenny, D. A., Kashy, D. A., Cook, W. L., \& Simpson, J. A. (2006). Dyadic data analysis (methodology in the social sciences). New York, NY: Guilford.

Kiernan, K. E., \& Mensah, F. K. (2009). Poverty, maternal depression, family status and children's cognitive and behavioural development in early childhood: A longitudinal study. Journal of Social Policy, 38, 569-588. https:// doi.org/10.1017/So047279409003250

Kofman, Y. B., Eng, Z. E., Busse, D., Godkin, S., Campos, B., Sandman, C. A.,... Yim, I. S. (2019). Cortisol reactivity and depressive symptoms in pregnancy: The moderating role of perceived social support and neuroticism. Biological Psychology. Advanced Online Publication. https://doi.org/10.1016/j. biopsycho.2019.01.016

Kotov, R., Gamez, W., Schmidt, F., \& Watson, D. (2010). Linking "big” personality traits to anxiety, depressive, and substance use disorders: A meta-analysis. Psychological Bulletin, 136, 768-821. https://doi.org/10.1037/a0020327

Lawrence, E., Barry, R. A., Brock, R. L., Bunde, M., Langer, A., Ro, E., ... Dzankovic, S. (2011). The relationship quality interview: Evidence of reliability, convergent and divergent validity, and incremental utility. Psychological Assessment, 23, 44-63. https://doi.org/10.1037/a0021096

Lawrence, E., Brock, R. L., Barry, R. A., Langer, A., \& Bunde, M. (2009). Assessing relationship quality: Development of an interview and implications for couple assessment and intervention. In E. Cuyler \& M. Ackhart (Eds.), Psychology of relationships (pp. 173-191). New York, NY: Nova Science..

Lengua, L. J., Bush, N. R. N. R., Long, A. C. A. C., Kovacs, E. A. E. A., Trancik, A. M. A. M., Lengua, J. L., ... Trancik, A. M. A. M. (2008). Effortful control as a moderator of the relation between contextual risk factors and growth in adjustment problems. Development and Psychopathology, 20, 509-528. https://doi.org/10.1017/Sog54579408000254

Letourneau, N. L., Tramonte, L., \& Willms, J. L. (2013). Maternal depression, family functioning and children's longitudinal development. Journal of Pediatric Nursing, 28, 223-234. https://doi.org/10.1016/j.pedn.2012.07.014

Liu, R. T., \& Alloy, L. B. (2010). Stress generation in depression: A systematic review of the empirical literature and recommendations for future study. Clinical Psychology Review, 30, 582-593. https://doi.org/10.1016/j. cpr.2010.04.010

MacCallum, R. C., Browne, M. W. M. W., \& Sugawara, H. M. (1996). Power analysis and determination of sample size for covariance structure modeling. Psychological Methods, 1, 130-149. https://doi.org/10.1037//1082-989X.1.2.130 
Malouff, J. M., Thorsteinsson, E. B., Schutte, N. S., Bhullar, N., \& Rooke, S. E. (2010). The five-factor model of personality and relationship satisfaction of intimate partners: A meta-analysis. Journal of Research in Personality, 44, 124127. https://doi.org/10.1016/j.jrp.2009.09.004

Milgrom, J., Gemmill, A. W., Bilszta, J. L., Hayes, B., Barnett, B., Brooks, J., ... Buist, A. (2008). Antenatal risk factors for postnatal depression: A large prospective study. Journal of Affective Disorders, 108, 147-157. https://doi.org/10.1016/j. jad.2007.10.014

Morren, M., Dulmen, S., Ouwerkerk, J., \& Bensing, J. (2009). Compliance with momentary pain measurement using electronic diaries: A systematic review. European Journal of Pain, 13, 354-365. https://doi.org/10.1016/j. ejpain.2008.05.010

Mullins-Sweatt, S. N., \& Widiger, T. A. (2006). The five-factor model of personality disorder: A translation across science and practice. In R. F. Krueger, \& J. L. Tackett (Eds.), Personality and psychopathology (pp. 39-70). New York, NY: Guilford Press.

Muthén, L. K., \&Muthén, B. O. (2010). Mplus user's guide (6th ed.). Los Angeles, CA: Author.

O’Hara, M. W., \& McCabe, J. E. (2013). Postpartum depression: Current status and future directions. Annual Review of Clinical Psychology, 9, 1-6o. https://doi. org/10.1146/annurev-clinpsy-050212-185612

O’Hara, M. W., \& Swain, A.M. (1996). Rates and risk of postpartum depression-a meta-analysis. International Review of Psychiatry, 8, 37-54. https://doi. org/10.3109/09540269609037816

Ormel, J., Bastiaansen, A., Riese, H., Bos, E. H., Servaas, M., Ellenbogen, M., ... Aleman, A. (2013). The biological and psychological basis of neuroticism: Current status and future directions. Neuroscience \& Biobehavioral Reviews, 37, 59-72. https://doi.org/10.1016/j.neubiorev.2012.09.004

Preacher, K. J., Rucker, D. D., \& Hayes, A. F. (2007). Addressing moderated mediation hypotheses: Theory, methods, and prescriptions. Multivariate Behavioral Research, 42, 185-227. https://doi.org/10.1080/00273170701341316

Rapaport, M. H., Clary, C., Fayyad, R., \& Endicott, J. (2005). Quality-oflife impairment in depressive and anxiety disorders. American Journal of Psychiatry, 162, 1171-1178. https://doi.org/10.1176/appi.ajp.162.6.1171

Robertson, E., Grace, S., Wallington, T., \& Stewart, D. E. (2004). Antenatal risk factors for postpartum depression: A synthesis of recent literature. General Hospital Psychiatry, 26, 289-295. https://doi.org/10.1016/j. genhosppsych.2004.02.006

Speranza, A. M., Ammaniti, M., \& Trentini, C. (2006). An overview of maternal depression, infant reactions and intervention programmes. Clinical Neuropsychiatry, 3, 57-68.

Starr, L. R. (2015). When support seeking backfires: Co-rumination, excessive reassurance seeking, and depressed mood in the daily lives of young adults. Journal of Social and Clinical Psychology, 34, 436-457. https://doi.org/10.1521/ jscp.2015.34.5.436 
Starr, L. R., \& Davila, J. (2012a). Temporal patterns of anxious and depressed mood in generalized anxiety disorder: A daily diary study. Behaviour Research and Therapy, 50, 131-141. https://doi.org/10.1016/j.brat.2011.11.005

Starr, L. R., \& Davila, J. (2012b). Cognitive and interpersonal moderators of daily co-occurrence of anxious and depressed moods in generalized anxiety disorder. Cognitive Therapy and Research, 36, 655-669. https://doi.org/10.1007/ s10608-011-9434-3

Substance Abuse and Mental Health Services Administration. (2017). Key substance use and mental health indicators in the United States: Results from the 2016 National Survey on Drug Use and Health (HHS Publication No. SMA 17-5044, NSDUH Series H-52). Retrieved from Substance Abuse and Mental Health Services Administration website: https://www.samhsa.gov/data/sites/ default/files/NSDUH-FFR1-2016/NSDUH-FFR1-2016.htm

Trudel, G., Villeneuve, L., Préville, M., Boyer, R., \& Fréchette, V. (2010). Dyadic adjustment, sexuality and psychological distress in older couples. Sexual and Relationship Therapy, 25, 306-315. https://doi. org/10.1080/14681991003702583

Uebelacker, L. A., \& Whisman, M. A. (2006). Moderators of the association between relationship discord and major depression in a national populationbased sample. Journal of Family Psychology, 20, 40-46. https://doi. org/10.1037/0893-3200.20.1.40

Waring, E. M., Patton, D., Neron, C. A., \& Linker, W. (1986). Types of marital intimacy and prevalence of emotional illness. Canadian Journal of Psychiatry, 31, 720-726. https://doi.org/10.1177/070674378603100805

Watson, D., Clark, L. A., \& Harkness, A. R. (1994). Structures of personality and their relevance to psychopathology. Journal of Abnormal Psychology, 103, 1831. https://doi.org/10.1037//0021-843X.103.1.103

Whisman, M. A. (1999). Marital dissatisfaction and psychiatric disorders: Results from the national comorbidity survey. Journal of Abnormal Psychology, 108, 701-706. https://doi.org/10.1037/0021-843X.108.4.701

Whisman, M. A. (2001). Depression and marital distress: Findings from clinical and community studies. In S. R. H. Beach (Ed.), Marital and family processes in depression (pp. 3-24). Washington, DC: American Psychiatric Association.

Whisman, M. A., \& Baucom, D. H. (2012). Intimate relationships and psychopathology. Clinical Child and Family Psychology Review, 15, 4-13. https://doi.org/10.1007/s10567-011-0107-2

Whisman, M. A., du Pont, A., Rhee, S. H., Spotts, E. L., Lichtenstein, P., Ganiban, J. M., ... Neiderhiser, J. M. (2018). A genetically informative analysis of the association between dyadic adjustment, depressive symptoms, and anxiety symptoms. Journal of Affective Disorders, 237, 18-26. https://doi.org/10.1016/j. jad.2018.04.105

Whisman, M. A., Robustelli, B. L., \& Labrecque, L. T. (2018). Specificity of the association between marital discord and longitudinal changes in symptoms of depression and generalized anxiety disorder in the Irish Longitudinal Study on Ageing. Family Process, 57, 649-661. https://doi.org/10.1111/famp.12351 
Whisman, M. A., Sheldon, C. T., \& Goering, P. (2000). Psychiatric disorders and dissatisfaction with social relationships: Does type of relationship matter? Journal of Abnormal Psychology, 109, 803-808. https://doi. org/10.1037//0021-843X.109.4.S03

Whisman, M. A., Uebelacker, L. A., \& Weinstock, L. M. (2004). Psychopathology and marital satisfaction: The importance of evaluating both partners. Journal of Consulting and Clinical Psychology, 72, 830-838. https://doi. org/10.1037/0022-006X.72.5.830

Woszidlo, A., \& Segrin, C. (2013). Direct and indirect effects of newlywed couples' neuroticism and stressful events on marital satisfaction through mutual problem solving. Marriage \& Family Review, 49, 520-545. https://doi.org/10.10 80/01494929.2013.772933

Yim, I. S., Tanner Stapleton, L. R., Guardino, C. M., Hahn-Holbrook, J., \& Dunkel Schetter, C. (2015). Biological and psychosocial predictors of postpartum depression: Systematic review and call for integration. Annual Review of Clinical Psychology, 11, 99-137. https://doi.org/10.1146/ annurevclinpsy-101414-020426 